\title{
Research on the Degradation of Oxacillin in Water by Strong Ionization Discharge
}

\author{
Rongjie YI, Qi ZHANG and Chengwu YI ${ }^{1}$ \\ School of Environment and Safety Engineering, Jiangsu University, Zhenjiang 212013, \\ China
}

\begin{abstract}
The degradation of oxacillin in aqueous solution by strong ionization dielectric barrier discharge (DBD) was explored. The effects of input voltage, initial $\mathrm{pH}$, initial concentration of solution and hydroxyl $(\cdot \mathrm{OH})$ inhibitor on the removal efficiency of OXA were investigated. The results showed that the removal efficiency of OXA with initial concentration of $20 \mathrm{mg} / \mathrm{L}$ reached $91.5 \%$ under the optimal treatment conditions of $3.8 \mathrm{kV}$ and $7.3 \mathrm{pH}$. With the higher voltage and the lower initial concentration, the removal effect was better. The $\mathrm{pH}$ of the solution has little effect on the removal efficiency, and the removal effect is the best in neutral aqueous solution. The inhibition effect of TBA was stronger than that of $\mathrm{CO} 32$ - and HCO3-. Moreover, $\cdot \mathrm{OH}$ was the main active substance in the process of strong ionization discharge, which played a major role in the removal of OXA. In addition, two main by-products were identified, the transformation pathways including hydroxylation $(+16 \mathrm{Da})$, decarboxylation $(-44 \mathrm{Da})$ were observed. This study provided a theoretical basis for the effective removal of antibiotics in water by strong ionization discharge.
\end{abstract}

Keywords. Dielectric barrier discharge, oxacillin, ozone, strong ionization discharge

\section{Introduction}

Penicillins is among the most used antibiotic classes in the world, $\beta$-lactam oxacillin (OXA) as a typical representative of penicillins for the treatment of aerobic Grampositive cocci [1]. OXA was often detected in wastewater plants (WWTPs) and natural water bodies, which will cause serious problems of the existence of drug-resistant bacteria and superbacteria in natural aqueous [2]. The main cause of the OXA pollution was due to the traditional process of the existing WWTPs cannot be effectively removed OXA. Therefore, it is necessary to find an effective way to eliminate OXA from aqueous.

In order to remove antibiotics from water, various advanced oxidation processes (AOP) were studied, such as ozonation, Fenton process, photochemical oxidation, photocatalysis [3-5]. These processes aim to generate strong oxygen oxidants, especially hydroxyl radicals $(\cdot \mathrm{OH})$, which can oxidize almost all organic compounds and react non selectively with various types of pollutants. However, the existing AOPs are mostly combined with activated carbon fiber, $\mathrm{Fe}_{3} \mathrm{O}_{4}, \mathrm{MnFe}_{3} \mathrm{O}_{4}, \mathrm{TiO}_{2}, \mathrm{ZnO}, \mathrm{CdS}, \mathrm{WO}_{3}$ and other catalysts [6-7]. Although the treatment effect is good, there are still has some problems

1 Corresponding Author, Chengwu YI, School of Environment and Safety Engineering, Jiangsu University, Zhenjiang 212013, China; Email: yichengwu0943@163.com 
such as high treatment cost and difficult catalyst recovery. With the development of plasma technology, especially the maturity of dielectric barrier discharge (DBD) technology, DBD technology has advantages in degradation and removal of antibiotic pollutants $[8,9]$. However, the existing DBD technology has a problem of low $\cdot \mathrm{OH}$ production. Therefore, how to produce $\cdot \mathrm{OH}$ with low cost and high yield is the research focus. In this paper, the strong ionization dielectric barrier discharge technology is proposed to treat $\mathrm{OXA}$ in aqueous, $\mathrm{O}_{3}$ concentration and the effects of voltage, $\mathrm{pH}$, initial concentration, $\cdot \mathrm{OH}$ inhibitors on the degradation efficiency are investigated.

\section{Material and Methods}

\subsection{Experimental Materials}

$\beta$-lactam oxacillin (OXA), phosphoric acid, acetonitrile, methanol, hydrochloric acid, sodium bicarbonate and sodium carbonate were purchased from China Pharmaceutical Co., Ltd. Tertiary butanol alcohol (TBA) was supplied by Aladdin Industrial Corporation Ltd. (China).

\subsection{Experimental Apparatus}

The experimental system includes DBD system and water treatment circulation system, as shown in figure 1. The strong ionization DBD reactor adopts dielectric barrier plate structure, the discharge electrode is made of sintered silver metal, its outer surface is sprayed with a thin dielectric layer $\left(\alpha-\mathrm{Al}_{2} \mathrm{O}_{3}\right)$ composed of dense insulating layer, and the grounding electrode is made of stainless steel shell. The discharge gap is $2.6 \mathrm{~mm}$. The sizes are $16 \mathrm{~cm} \times 16 \mathrm{~cm} \times 0.5 \mathrm{~cm}$ and $16 \mathrm{~cm} \times 16 \mathrm{~cm} \times 0.2 \mathrm{~cm}$, respectively.

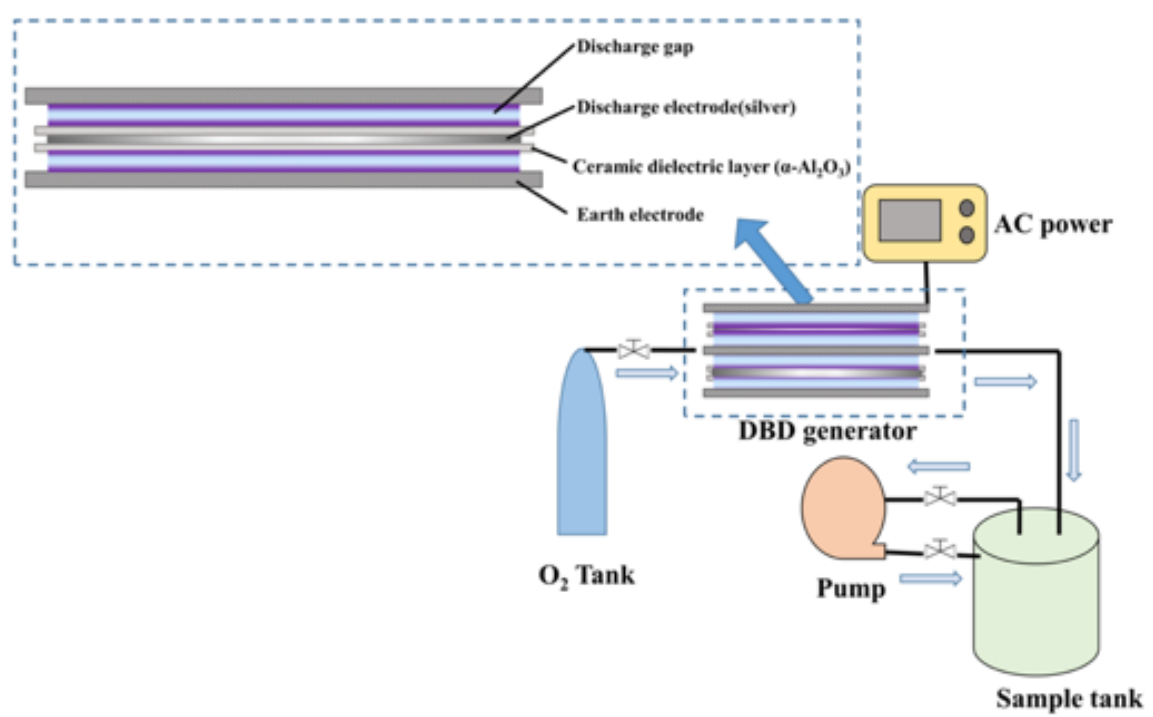

Figure 1. The flow-process diagram of water treatment systems of strong ionization discharge. 
The power supply is CTP2000k power supply with discharge frequency of $5-20 \mathrm{kHz}$ and discharge voltage of $0-30 \mathrm{kV}$. The electric field strength $\left(\mathrm{E}_{\mathrm{g}}\right)$ formed between the plates of the generator is as high as $800 \mathrm{Td}$, the electron density between the plates is $1015 / \mathrm{cm}^{3}$, the average electron energy $\left(\mathrm{T}_{\mathrm{e}}\right)$ is increased to $13 \mathrm{eV}$, and the energy density of the gap discharge is $2.1 \mathrm{w} / \mathrm{cm}^{2}$, which is called strong ionization discharge [10]. Under the action of $2 \mathrm{t} / \mathrm{h}$ circulating pump, Venturi jet is added in the water circulation system to increase the reaction between active substances and pollutants, which can be recycled and the removal effect is optimized. The degradation experiment of $20 \mathrm{mg} / \mathrm{L} \mathrm{OXA}$ solution was carried out by strong ionization DBD reaction system. The concentrations of OXA in water samples were detected at $5 \mathrm{~min}, 10 \mathrm{~min}, 30 \mathrm{~min}$ and $60 \mathrm{~min}$, respectively.

\subsection{Analytical Methods}

The absorption wavelength of OXA was measured by UV-visible spectrophotometer (UV22450, Shimadzu, Japan). The concentration of OXA was determined by high performance liquid chromatography (HPLC, LC-1260, Agilent, USA) and waters XBridge C18 column at $225 \mathrm{~nm}$. The eluent was composed of phosphate buffer $(0.02$ $\mathrm{mmol} / \mathrm{L}, \mathrm{pH} 5) /$ acetonitrile/methanol, $64 / 27 / 9(\mathrm{~V} / \mathrm{V} / \mathrm{V})$, and the flow rate was $0.4 \mathrm{ml} / \mathrm{min}$. High concentration ultraviolet dissolved water ozone analyser (CL-7685, B\&C electzanice, Italy) was used to measure the concentrations of $\mathrm{O}_{3}$ generated during the process. The intermediate byproducts of OXA were measured by high-performance liquid chromatography mass spectrometry (LC/MS/MS) (7890B-5977B, Agilent, USA).

\section{Results and Discussion}

\subsection{Effects of Input Voltage on OXA Degradation}

The input voltage $U$ affects the production of active particles and the removal efficiency $\eta$ of pollutants. As shown in figure 2 , under $U$ of $2.1 \mathrm{kV}, 3.0 \mathrm{kV}$ and $3.8 \mathrm{kV}, \eta$ of OXA increased to $72.0 \%, 75.4 \%$ and $83.6 \%$, respectively, after 30 min strong ionization DBD treatment. With the extension of reaction time, $\eta$ increased to $82.3 \%, 87.4 \%$ and $91.5 \%$ respectively. Similarly, figure 3 showed that the kinetic constant $R$ can be enhanced when the increased of $U$. At $U$ of $3.8 \mathrm{kV}, R$ can reach up to $0.049 \mathrm{~min}^{-1}$. As shown in figure 4, under the same reaction time and different voltage, the amount of $\mathrm{O}_{3}$ was also different. When $U$ reaches $3.8 \mathrm{kV}$, the $\mathrm{O}_{3}$ concentration reaches $14.3 \mathrm{mg} / \mathrm{L}$. It is worth emphasizing that the concentration of $\mathrm{O}_{3}$ produced by the strong ionization DBD reactor increased with the increase of $U$. Therefore, increasing $U$ can improve $\eta$ of OXA solution, and the strong ionization DBD under $U$ is a feasible way to improve $\eta$ of antibiotic wastewater. 


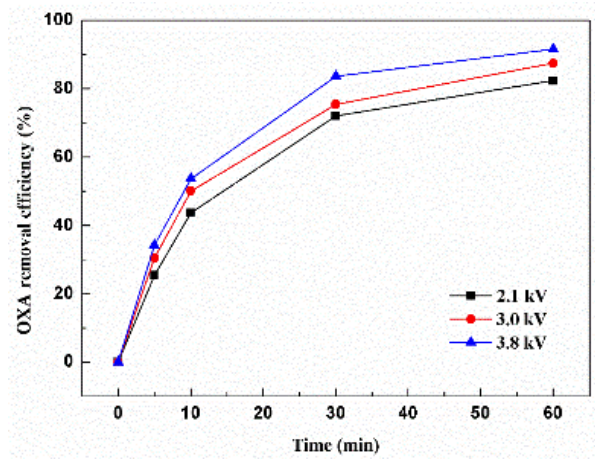

Figure 2. Effect of the input voltage on OXA removal efficiency.

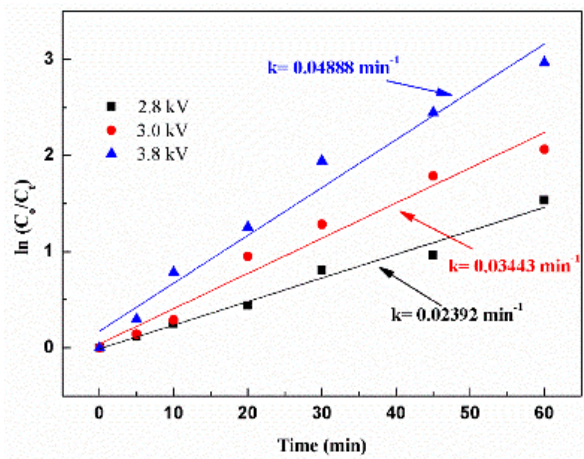

Figure 3. Effect of the input voltage on OXA degradation kinetic constant.

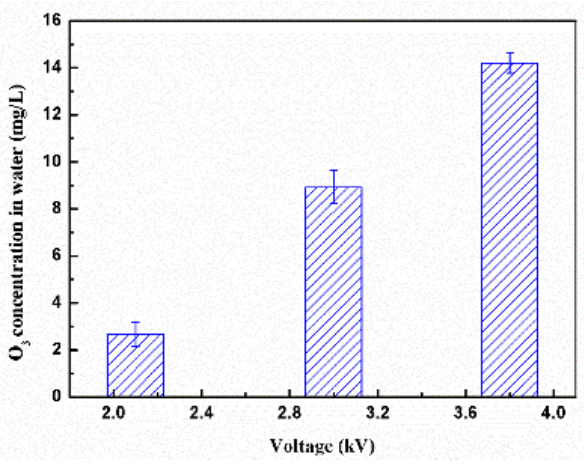

Figure 4. $\mathrm{O}_{3}$ concentration in water on different voltage.

\subsection{Effects of pH on OXA Degradation}

The $\mathrm{pH}$ value of the solution has an effect on the amounts of active particles and the reaction mechanism between active particles and pollutants. Therefore, it is of great significance to study the degradation of OXA solution by strong ionization discharge at different $\mathrm{pH}$ values. As illustrated in figure 5 summarizes the removal efficiency of water samples under different treatment time and $\mathrm{pH}$ conditions. Under the same conditions, when the $\mathrm{pH}$ values are 3.8, 7.3 and 9.8 respectively, $\eta$ of OXA after 60 min treatment are $85.3 \%, 91.5 \%$ and $80.5 \%$ respectively. Analogously, greater kinetic constant can be obtained at natural $\mathrm{pH}$ (7.3), as shown in figure 6, showing that $\mathrm{pH}$ value has little effect on $\eta$ of quinoline. It can be seen that OXA has a better degradation effect under neutral conditions, and $\eta$ under alkaline conditions is better than that under acidic conditions. This can be explained by the fact that $\mathrm{O}_{3}$ is more stable but less soluble under acidic conditions [11, 12]. In addition, under alkaline conditions, $\cdot \mathrm{OH}$ can promote the decomposition of $\mathrm{O}_{3}$, and $\mathrm{O}_{3}$ can produce more $\mathrm{O}_{2}$ [13]. Therefore, a large number of active particles can degrade OXA faster. The results show that the strong ionization discharge DBD system is suitable for the removal of pollutants in both acidic and alkaline solutions. 


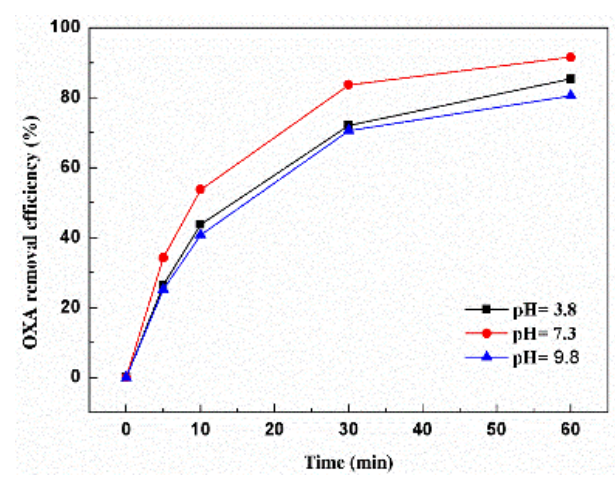

Figure 5. Effect of the $\mathrm{pH}$ on OXA removal efficiency.

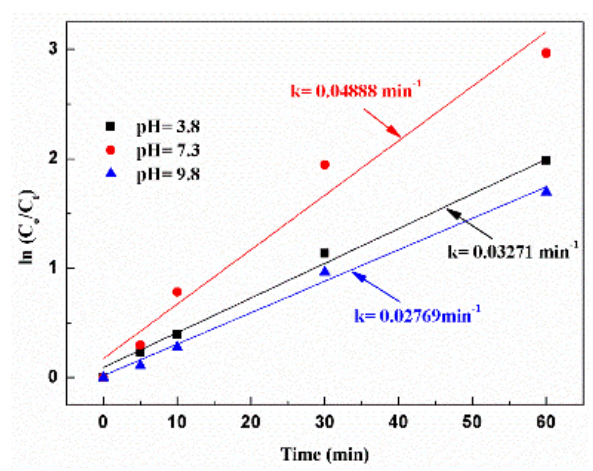

Figure 6. Effect of the pH on OXA degradation kinetic constant.

\subsection{Effects of Initial Concentration on OXA Degradation}

Under the conditions of $U 3.8 \mathrm{kV}$, discharge frequency $20 \mathrm{kHz}$ and $\mathrm{pH}$ value 7. 3, the effect of initial concentration on $\eta$ of OXA was investigated. As shown in figure 7 , after 60 min strong ionization discharge treatment, $\eta$ of OXA decreased with the extension of time, the initial concentration of OXA increased from $5 \mathrm{mg} / \mathrm{L}$ to $40 \mathrm{mg} / \mathrm{L}, \eta$ of OXA were $99.0 \%, 91.5 .8 \%$ and $78.7 \%$, respectively. Similarly, figure 8 showed that $R$ can be decreased when the initial concentration on quinoline were increased, which can reach $0.065 \mathrm{~min}^{-1}, 0.049 \mathrm{~min}^{-1}$ and $0.024 \mathrm{~min}^{-1}$. The higher the initial concentration of the solution, the more active particles are consumed by the strong ionization discharge, $\eta$ is reduced. It is further confirmed that the high concentration of pollutants in water is greatly affected by the strong ionization discharge.

\subsection{Effects of $\cdot$ OH Inhibitors on OXA Degradation}

Based on the theory of dielectric barrier discharge, not only $\mathrm{O}_{3}$, but also $\cdot \mathrm{OH}$ is one of the representatives of active particles in strong ionization discharge system. However, the effects of different inhibitors on the degradation of OXA by strong ionization discharge need to be investigated. As shown in figure 9 , when the concentrations of TBA, $\mathrm{CO}_{3}{ }^{2-}$ and $\mathrm{HCO}_{3}{ }^{-}$were $30 \mathrm{mg} / \mathrm{L}, \eta$ of OXA were $46.1 \%, 70.2 \%$ and $54.5 \%$ respectively in the 60 min strong ionization discharge oxidation process. $R$ decreased from 0.049 $\mathrm{min}^{-1}$ to $0.021 \mathrm{~min}^{-1}, 0.014 \mathrm{~min}^{-1}$ and $0.011 \mathrm{~min}^{-1}$ in strong ionization discharge DBD system with TBA, $\mathrm{CO}_{3}{ }^{2-}$ and $\mathrm{HCO}_{3}{ }^{-}$, respectively (figure 10 ). $\eta$ was $91.5 \%$ without any inhibitors. The results showed that the addition of inhibitors had obvious inhibition on the degradation of OXA, and TBA had the strongest inhibition effect. These inhibitors (TBA, $\mathrm{CO}_{3}{ }^{2-}$ and $\mathrm{HCO}_{3}{ }^{-}$) can inhibit the formation of $\cdot \mathrm{OH}$. Therefore, $\cdot \mathrm{OH}$ is the main active particles of OXA degradation [12]. 


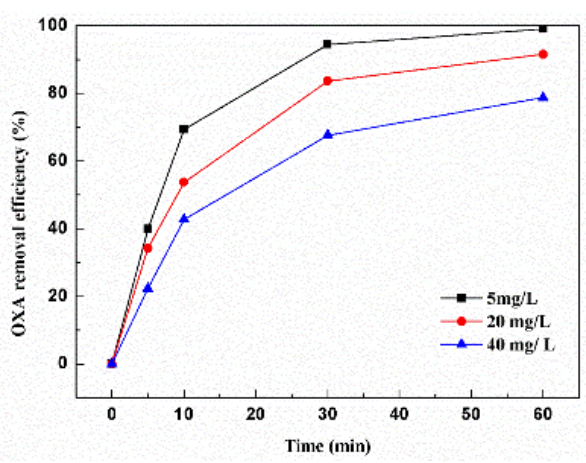

Figure 7. Effect of the initial concentration on OXA removal efficiency.

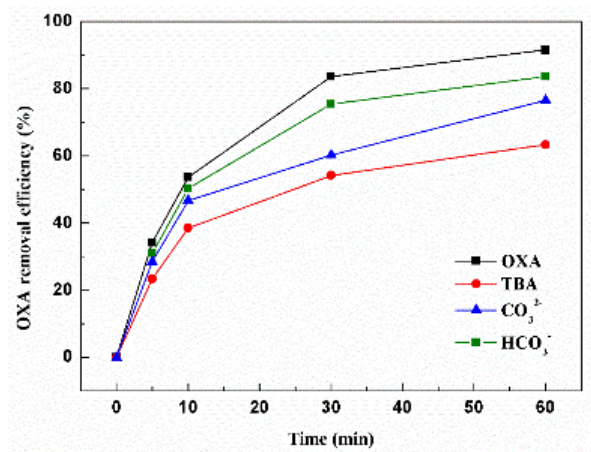

Figure 9. Effect of the $\cdot \mathrm{OH}$ inhibitors on OXA removal efficiency.

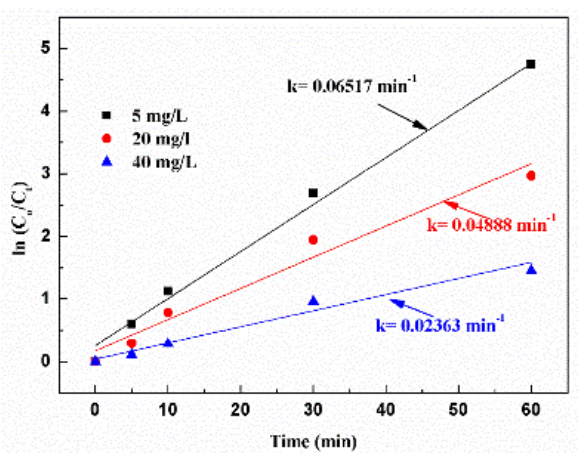

Figure 8. Effect of the initial concentration on OXA degradation kinetic constant.

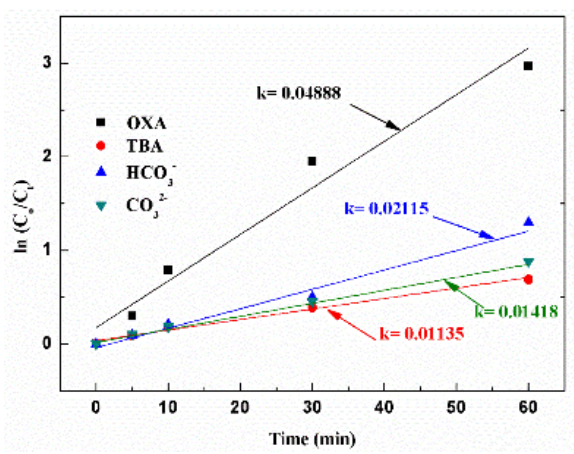

Figure 10. Effect of the $\cdot \mathrm{OH}$ inhibitors on OXA degradation kinetic constant.

\subsection{Possible Degradation Mechanism and Pathway of OXA}

Based on the LC-MS results the two by-products of OXA (m/z 420, m/z 374) identified and as indicated in figure 11, different transformation pathways were proposed including hydroxylation (+16 Da), decarboxylation (-44 Da). Compound $\mathrm{m} / \mathrm{z} 420$ was found in the oxidation process, which could have been generated from the hydrolysis of OXA at the beta-lactam ring. This is a common degradation pathway that has been previously reported for the removal of B-lactam antibiotics by non-thermal plasma, the photoFenton process and the sonochemical treatment $[13,14]$. Further reaction of the product $\mathrm{m} / \mathrm{z} 420$ with $\cdot \mathrm{OH}$ results in the decarboxylation, which could evolve into $\mathrm{m} / \mathrm{z} 374$, might be resulted from the strong electrophilic agent property of $\cdot \mathrm{OH}$, favoring the decarboxylation process.

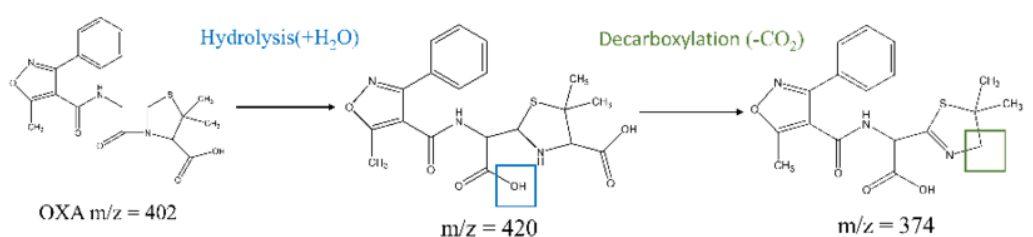

Figure 11. Proposed reaction pathway for the degradation of OXA by a strong ionization discharge. 


\section{Conclusions}

In order to solve the problem of low efficiency and poor treatment ability in traditional treatment methods, a strong ionization DBD reaction system was studied to degrade OXA in water. The effects of different $U$, initial $\mathrm{pH}$ value, initial concentration and $\mathrm{OH}$ inhibitors dosage on $\eta$ of OXA were investigated. The results showed that $\eta$ of OTC increased with the increase of $U$ and the decrease of initial concentration. At the same time, the addition of TBA, $\mathrm{CO}_{3}{ }^{2-}$ and $\mathrm{HCO}_{3}$ effectively inhibited the removal of OXA in aqueous solution by inhibiting the existence of hydroxyl groups. It should be noted that $\mathrm{pH}$ has little effect on $\eta$ of $\cdot \mathrm{OH}$, and the best removal condition is neutral. Under different $U$, with the higher $U$, the more $\mathrm{O}_{3}$ was produced in the system. In addition, two main byproducts $(\mathrm{m} / \mathrm{z} 420$ and $\mathrm{m} / \mathrm{z} 374)$ from OXA of the strong ionization discharge progress were observed.

\section{Acknowledgements}

Thanks to the National Natural Science Foundation of China (32071521), the Postgraduate Research \& Practice Innovation Program of Jiangsu Province (No. KYCX18_2272), the Priority Academic Program Development of Jiangsu Higher Education Institutions (PAPD) and Jiangsu Collaborative Innovation Center of Technology and Material of Water Treatment for their support of this work.

\section{References}

[1] Nomura R, Nakaminami H, Takasao K, Muramatsu S and Noguchi N 2020 A class a $\beta$-lactamase produced by borderline oxacillin-resistant staphylococcus aureus hydrolyzes oxacillin Journal of Global Antimicrobial Resistance 22.

[2] Watkinson A J, Murby E J, Kolpin D W and Costanzo S D 2009 The occurrence of antibiotics in an urban watershed: from wastewater to drinking water Sci. Total Environ 407 2711-2723.

[3] Hua Z H, Guo K H, Kong X J, Lin S K, Wu Z H, Wang L P, Huang H and Fang J Y 2019 PPCP degradation and DBP formation in the solar/free chlorine system: Effects of $\mathrm{pH}$ and dissolved oxygen Water Res. 150 77-85.

[4] Choi S, Sim W, Jang D, Yoon Y, Ryu J, Oh J, Woo J S, Kim Y M and Lee Y 2020 Antibiotics in coastal aquaculture waters: Occurrence and elimination efficiency in oxidative water treatment processes Hazard Mater. 396122585.

[5] Watkinson A J, Murby E J and Costanzo S D 2007 Removal of antibiotics in conventional and advanced wastewater treatment: Implications for environmental discharge and wastewater recycling Water Res. 41 4164-4176.

[6] Wang J, Sun Y B, Feng J W, Xin L and Ma J Z 2016 Degradation of triclocarban in water by dielectric barrier discharge plasma combined with $\mathrm{TiO}_{2}$ /activated carbon fibers: Effect of operating parameters and by products identification Chem. Eng. J. 300 36-46.

[7] Uslu M O and Balcioglu I A 2009 Comparison of the ozonation and Fenton process performances for the treatment of antibiotic containing manure Sci. Total Environ. 407 3450-3458.

[8] Yi R J, Guo H, Wang H J, Du D L, Zhang Q and Yi C W 2021 Multiple production of highly active particles for oxytetracycline degradation in a large volume strong ionization dielectric barrier discharge system: Performance and degradation pathways Sep. Purif. Technol. 274119103.

[9] Yi R J, Yi C W, Du D L, Zhang Q, Yu H J and Yang L 2021 Research on quinoline degradation in drinking water by a large volume strong ionization dielectric barrier discharge reaction system Plasma Sci. Technol. 23 (8).

[10] Zhang Y B, Bai M D, Chen C, Meng X Y, Tian Y P, Zhang N H and Yu Z 2013 OH treatment for killing of harmful organisms in ship's ballast water with medium salinity based on strong ionization discharge Plasma Chem. Plasma Process 33 751-763. 
[11] Bao Y, Lee W J, Lim T T, Wang R and Hu X 2019 Pore-functionalized ceramic membrane with isotropically impregnated cobalt oxide for sulfamethoxazole degradation and membrane fouling elimination: Synergistic effect between catalytic oxidation and membrane separation Appl. Catal. B. Environ. 254 37-46.

[12] Fu Y Y, Wu G, Geng J J, Li J C, Li S N and Ren H Q 2019 Kinetics and modeling of artificial sweeteners degradation in wastewater by the UV/persulfate process Water Res. 150 12-20.

[13] Lueddeke F, Hess S, Gallert C, Winter J, Guede H and Loeffler H 2015 Removal of total and antibiotic resistant bacteria in advanced wastewater treatment by ozonation in combination with different filtering techniques Water Res. 69 243-251.

[14] Magureanu M, Piroi D and Mandache N B 2011 Degradation of antibiotics in water by non-thermal plasma treatment Water Research 45 (11) 3407-3416. 